\title{
Repair of supracondylar femur fracture in a Lhasa Apso dog by cross pinning technique: A case report
}

\author{
M. Raghunath ${ }^{a}$, (D) P. Vidya Sagar ${ }^{b}$, P. Ravi Kumar ${ }^{b}$, B. Sailaja ${ }^{b}$ and V. S. C. Bose \\ ${ }^{\mathrm{a}}$ Professor, Department of Teaching Veterinary Clinical Complex, SVVU, Gannavaram, Krishna (Dt), Andhra \\ Pradesh-521102. \\ b Assistant Professor, Department of Teaching Veterinary Clinical Complex, SVVU, Gannavaram, Krishna (Dt), \\ Andhra Pradesh-521102. \\ c Professor (Rtd.), Department of Teaching Veterinary Clinical Complex, SVVU, Gannavaram, Krishna (Dt), \\ Andhra Pradesh-521102.
}

Corresponding author: P. Vidya Sagar | email: doctorpentyala@gmail.com Co-author: MR:drraghupau@gmail.com; PRK: ravikumarpallitvm1018@gmail.com; SB: sailajabagadi@gmail.com; VSCB: vemulapalli.bose@gmail.com

Received: 27-11-2020, Accepted: 12-12-2020, Published online: 25-12-2020

\begin{abstract}
A three-year-old Lhasa apso was presented with a history of fall from a height resulting in limping of the right hind limb. It was radiographically diagnosed as a complete, transverse, displaced supracondylar fracture of the femur. The fractured fragments were reduced and stabilized by cross pinning technique using $\mathrm{k}$-wires, and the weight-bearing was seen from $3^{\text {rd }}$ post-operative day. On the seventh post-operative day, the same animal was presented with limping on the same limb due to sudden fall from a height again. Radiographically it was confirmed as catastrophic implant failure with collapsed fragments. In surgery, the migrated pins were removed and the fragments were restabilized by cross pinning using k-wires. Post-operative application of robertjones bandage and regular physiotherapy was provided. The animal showed complete weight-bearing from $10^{\text {th }}$ postoperative day, and the full radiographic union was observed on $35^{\text {th }}$ post-operative day.
\end{abstract}

Keywords: $\quad$ supracondylar fracture, k-wires, robertjones bandage, cross pinning technique

doi: https://doi.org/10.51128/jfas.2020.A025 | How to cite this article: Raghunath, M., Sagar, P. V., Kumar, P.R., Sailaja, B. and Bose, V.S.C. 2020. Repair of supracondylar femur fracture in a Lhasa Apso dog by cross pinning technique: A case report. Journal of Food and Animal Sciences, 01(02): $140-143$.

Copyright: Raghunath et al., 2020. Open Access. This article is distributed under the terms of the Creative Commons Attribution 4.0 International License (http://creativecommons.org/licenses/by/4.0/), which permits unrestricted use, distribution, and reproduction in any medium, provided you give appropriate credit to the original author(s) and the source, provide a link to the Creative Commons license, and indicate if changes were made. The Creative Commons Public Domain Dedication waiver (http://creativecommons.org/publicdomain/zero/1.0/) applies to the data made available in this article, unless otherwise stated. 


\section{Introduction}

The distal femur fractures include supracondylar fracture, intercondylar or epiphyseal fractures. All the supracondylar fractures are transverse and occasionally oblique (Bojrab, 1975) and needs arthrotomy of the stifle joint to expose the distal fragment. Due to little availability of bone distal to fracture, presence of soft cancellous bone and caudal bowing of the distal epiphysis of femur with respect to diaphysis (Piermetti and Flo, 1997), the application of intramedullary pins and bone plates is limited. Hence in these particular cases, small transfixation pins / $\mathrm{k}$-wires in a cross pattern are used. The present report describes a case of supracondylar femoral fracture repair in a Lhasaapso dog and its management after catastrophic implant failure.

\section{History and Clinical Observations}

A 3 year, male, Lhasa apso, of $8 \mathrm{Kg}$ body weight was presented to the Teaching Veterinary Clinical Complex, NTR College of Veterinary Science, Gannavaram, with a complaint limping of the right hind limb after falling from a height three days back.

Physical examination revealed crepitating sound at the distal end of the femur along with swelling. Cranio caudal view and latero medial radiographic views of the affected part revealed a transverse displaced supracondylar fracture of the right femur (Fig.1).

\section{Treatment}

Preoperatively the fractured limb was stabilized with Robertjones bandage along with administration of Inj Melonex @ 0.2mg/Kg.B.wt. for 3 days. The animal was prepared for surgery after aseptic preparation of the limb. The animal was premedicated with Inj. Atropine sulphate @ 0.04 $\mathrm{mg} /$ Kg.B.wt subcutaneously and general anaesthesia was induced with combination of Ketamine and Diazepam @ 5mg/ Kg.B.wt and 0.5 mg/ Kg.B.wt respectively mixed in a single syringe. The anesthesia was maintained with 2-3\% Isoflurane after cuffed endotracheal intubation using an anaesthetic machine. The fractured site was approached by giving lateral patellar curvilinear skin incision and lateral arthrotomy incision (Raghunath et al., 2012).
The fractured fragments were exposed and reduced. Three k-Wires of $1.2 \mathrm{~mm}$ diameter were passed from medial and lateral condyles of femur, 2 from each side to cross the fracture line to get embedded in the opposite diaphyseal cortices (Fig.2).

The joint capsule, fascialata and subcutaneous tissue were sutured using simple continuous pattern and then the skin in a routine manner (Nazhvani et al., 2013). Postoperative Robert Jones bandage was applied along with administration of Inj. cefotaxime @ 10mg/ Kg.B.wt and Inj. melonex @ 0.2 mg/ Kg.B.wt for 5 days. The animal started partial weight bearing from $3^{\text {rd }}$ post-operative day. The same a nimal was presented on $10^{\text {th }}$ post-operative day with the complaint of limping of the operated limb due to falling again from table.

Physical examination revealed pain on palpation at the affected area and after radiographic evaluation it was confirmed as catastrophic implant failure with dislodged fragments (Fig.3). It was decided to reoperate the animal and the affected area was stabilized with Robertjones bandage till the date of surgery. The surgery was performed again under the above said anaesthetic protocol. The migrated pins were removed and the bone edges were nibbled with the rounger. Two $\mathrm{k}$-wires of $3 \mathrm{~mm}$ diameter were used in similar manner as described above. Post operative Robert Jones bandaging was done and regular physiotherapy was provided along with aseptic dressing of the wound.

\section{Results and Clinical Outcome}

The animal showed partial weight-bearing from $7^{\text {th }}$ post-operative day after resurgery. Radiographic examination at $2^{\text {nd }}$ post-operative week showed signs of callus formation, intact implant and fracture fragments. The animal showed complete weightbearing and free-range motion of the stifle joint by the end of the $2^{\text {nd }}$ post-operative week. By the end of $8^{\text {th }}$ post-operative week complete union of fractured fragments was noticed on radiographic examination with no evidence of fracture line and the animal recovered uneventfully (Fig.4)

\section{Discussion}

Out of all long bone fractures, $45 \%$ are femur fractures. In the femur fractures of small animals, 
$25 \%$ represent distal femoral fractures, including supracondylar fractures, intercondylar or epiphyseal fractures in which the former was common in mature a nimals and the later one was seen in Young ones (Nazhvani et al., 2013). Mostly all the supracondylar fractures in small animals are transverse and occasionally oblique (Bojrab, 1975), as also seen in the present case. These supracondylar fractures are

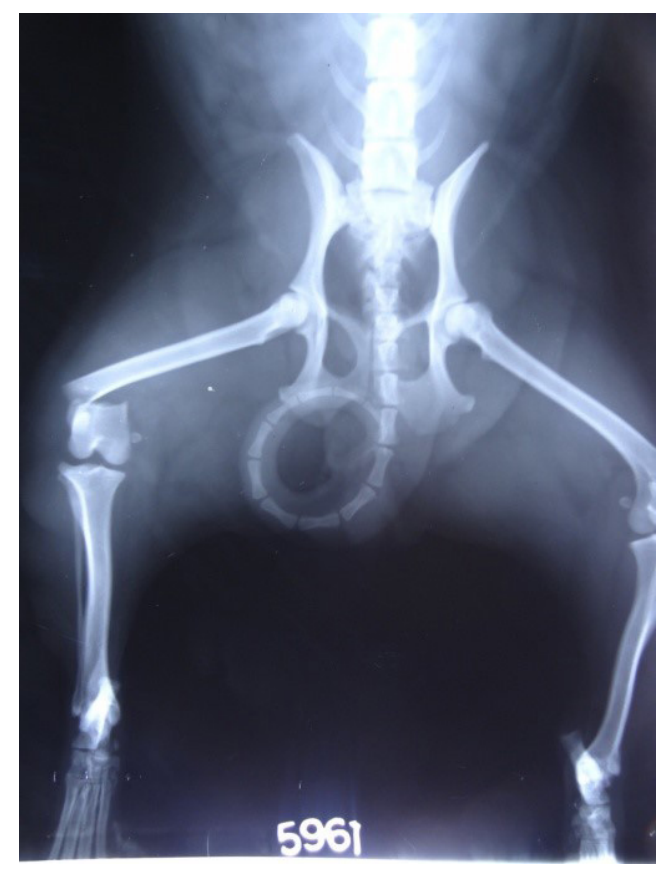

Fig. 1: Photo radiograph showing transverse displaced supracondylar fracture of right femur

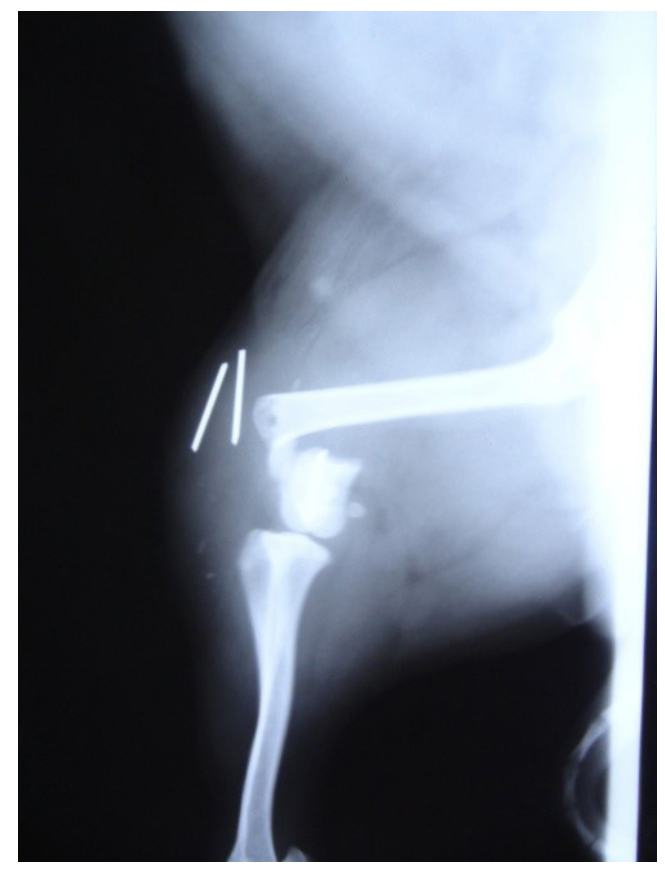

Fig. 3: Photo radiograph showing catastrophic implant failure with dislodged fragments difficult to manage because of less availability of bone distally to the fracture line, fracture line location nearer to the joint, and more forces acting on it. In the present case it was decided to reduce and repair the fracture fragments by cross pinning technique. The post-operative application of Robert Jones bandage and regular physiotherapy of the affected limb prevented joint rigidity. Failure of pins and fracture

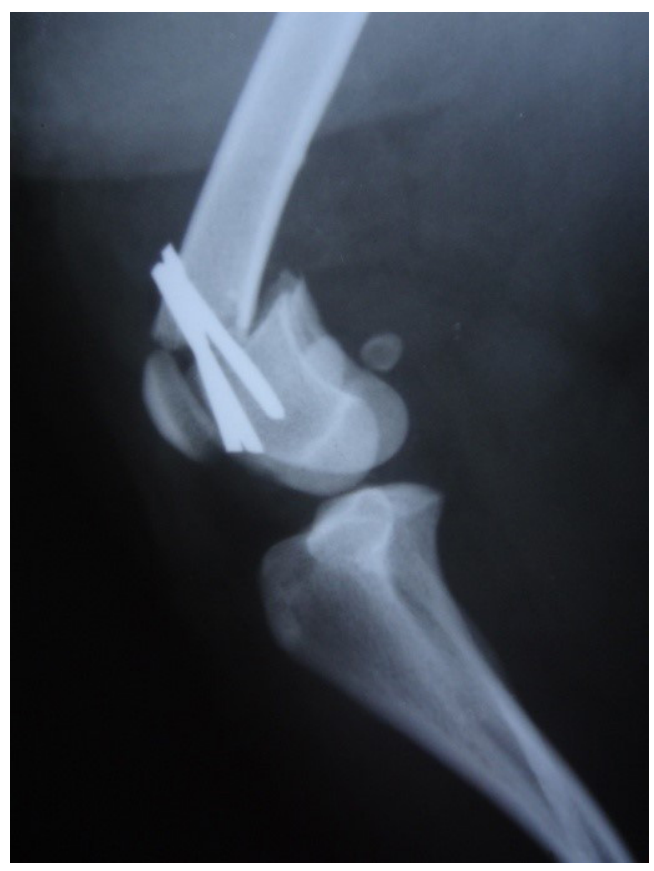

Fig. 2: Photo radiograph showing reduction of fragments with $\mathrm{k}$-wire cross pinning technique

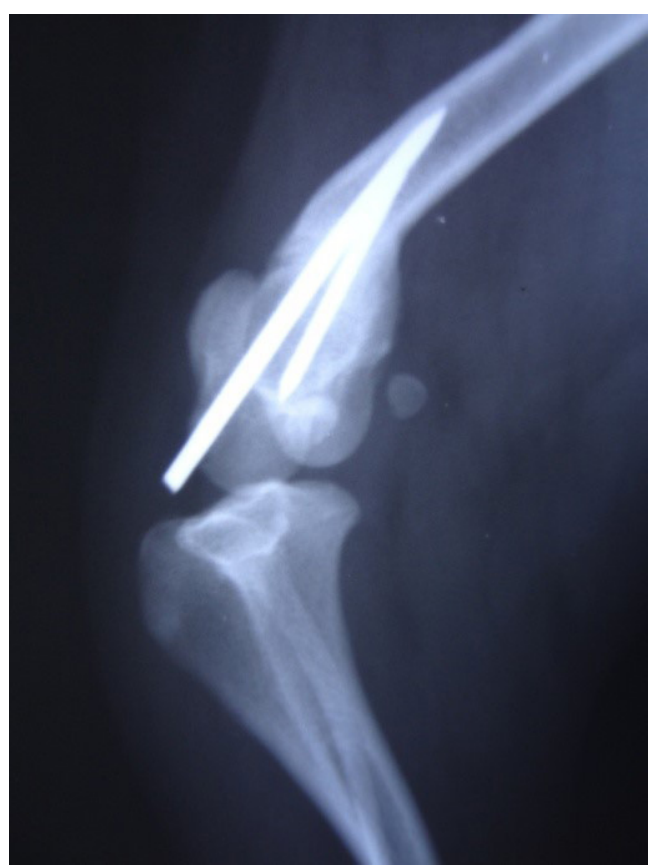

Fig. 4: Photo radiograph showing complete union of fractured fragments by the end of $8^{\text {th }}$ post-operative week 
dislodgement was observed due to excessive force on the fracture line on $7^{\text {th }}$ post-operative day after fall from the table. In post-operative complications like the migration of pins, the implant should be repositioned or removed surgically (Halling et al. 2002). In the present case, the a nimal was reoperated, the migrated pins were removed and new pins were applied to repair the fracture line. The fractures are prone to quadriceps contractions and may lead to stifle stiffness as opined by Piermetti and Flo, 1997 and Bardet and Hohn, 1983. In the present case, the cross pinning technique provided sufficient fracture stability even though the a nimal was reoperated after earlier implant failure.

\section{Authorship contribution statement}

M.Raghunath : Conceptualization, Methodology, Writing-Original draft; P.Vidya Sagar.: Conceptualization, Methodology, Writing-Original draft; P. Ravi Kumar: Validation; B. Sailaja: Visualization, Investigation; VSC Bose: Reviewing and Editing

\section{Acknowledgments}

The Authors acknowledge and thank Sri Venkateswara Veterinary University, Tirupati, Gannavaram, Krishna (Dt), Andhra Pradesh-521102

\section{Funding}

There is no substantial funding to be stated.

\section{Declaration of Competing Interest}

The authors declare that no conflict of interest for the study conducted

\section{References}

Bardett, J.F. and Hohn, R.B. 1983. Quadriceps contracture in dogs. J. Am Vet med Assoc 183: 680-685.

Bojrab, M.J. 1975. Current techniques in small animal surgery. $2^{\text {nd }}$ Edn., Philadelphia, Lea and Febiger. PP:459-460.

Halling, K.B., Lewis, D.D., Cross, A.R., Kerwin, S.C., Smith, B.A. and Kubilis, P.S. 2002. Complications rate and factors affecting outcome of olecranon osteotomies repaired with pin and tension-band fixation in dogs. Can Vet J. 43:528-534.

Nazhvani, D.S., Jahromi, R., Foroud, M., Vesal, N. and Hooman, F. 2013. Surgical repair of distal femoral fracture in a wild gray wolf (Canis lupus). Iranian Journal of Veterinary Research, 14(2): 165-168.

Piermetti, D.L. and Flo, G.L. 1997. Fractres of the femur and patella. In: Handbook of small animal orthopaedics and fracture repair, by Brinker, Piermattei and Flo ( $3^{\text {rd }}$ Ed.) WB Saunders, Philadelphia, pp:469-75.

Raghunath, M., Bishnoi, A.K., Mohindroo, J. and Prabhakar, V. 2012. Cross-pinning and Lagscrew compression for the management of supracondylar and intercondylar femoral fracture in a dog. Intas Polivet, 13(II): 416-419. 